\title{
Evaluation of "CLE" an Intermediate Family Centered Developmental Care Program Based on the Theoretical Concept of the Newborn Individualized Developmental Care and Assessment Program (NIDCAP)
}

\author{
Druart Da, Grevesse $L^{b}$, Janssens $K^{c}$, Tackoen $M^{a}$, Van Herreweghe ${ }^{a}$
}

a NICU St Pierre University Hospital, Brussels NIDCAP ${ }^{\circledR}$ Training Center, Brussels, Belgium

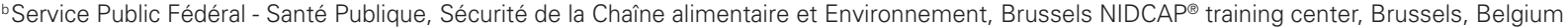

'Service Public Fédéral - Santé Publique, Sécurité de la Chaîne alimentaire et Environnement, UZ Leuven, Belgium Training Center

\section{Aims/Purpose}

The Belgian government has always been very supportive concerning the implementation of individualized family-centered developmental care in newborn units. Since 2012 the implementation of NIDCAP has been subsidized by the government. This project evolution demonstrated the benefit of NIDCAP on care practices $^{1}$ and revealed the need for intermediate NIDCAP-based programs. ${ }^{2,3}$ This requires facilitation of NIDCAP implementation in Newborn Intensive Care Units (NICUs) on the one hand, and development of programs adapted to the reality of Intermediate Newborn Care Units on the other hand. These findings matched the observations of the Brussels NIDCAP training center.

For a couple of years, a group of Belgian NIDCAP professionals worked on an intermediate developmental care program. This program, called CLE (Compréhension du Langage de l'Enfant), was finalized three years ago after consulting other NIDCAP trainers. It is similar to the Family and Infant Neurodevelopmental Education (FINE) program.

The Belgian federal government funds NIDCAP, FINE and CLE training in Belgium.

\section{Methods}

Two questionnaires were conceived:

- The first was designed for CLE trainees and evaluates training, impact on caregiving, collaboration with families, and the trainees' feedback on implementation in the newborn unit.

- The second questionnaire was designed for parents and evaluates parent satisfaction with the guidance received, and the impact on parent involvement in decision-making and their ability to understand their baby.

\section{Results}

In Belgium, 11 hospitals received financial support for CLE training. Between October 2017 and June 2018, 34 caregivers started the CLE program and 32 trainees completed the training in six hospitals.
- 97\% indicated the CLE training has induced a lot of changes in the way they take care of babies.

- $97 \%$ indicated training led to changes in the way they work with families.

- $100 \%$ said the training helped them to question their own practices.

- $97 \%$ said the training helped them to reflect on unit care practices.

- $97 \%$ are satisfied with the training quality.

- $94 \%$ indicated the training met their expectations.

42 questionnaires were completed by parents.

- $95 \%$ indicated the CLE program helped them to better understand their baby.

- $93 \%$ felt encouraged to take part in decision-making.

- $95 \%$ thought the CLE program is helpful to parents.

\section{Conclusion}

The CLE program promotes the practice of family-centered developmental care. It meets professionals' and parents' expectations. An ongoing assessment of the evolution of developmental care practices in Belgian hospitals carried out by the authorities, should highlight the impact of this training on future results at the national level. The CLE program does not replace formal NIDCAP training but can help prepare units for the training as well as reduce the gap between practices carried out by NIDCAP certified professionals and the rest of the team. It meets the needs and specificities of Level 2 newborn units in Belgium.

References

1. Van Herreweghe I, Druart D, Janssens K, Clercx A, Claesen M, Tackoen M. A healthcare policy aiming to optimize parent-baby bonding in hospitals: The Belgian example. Revue de Médecine.Périnatale. 2016; 8(3):133-40 (In French).

2. Als H. Program Guide - NIDCAP: An Educational Training Program for Health Care Professionals. NIDCAP Federation International. 2015. Retrieved from http://Nidcap.org.

3. Als H. Toward a synactive theory of development. Promise for the assessment of infant individuality. Infant Mental Health Journal. 1982; 3:229-43. 